\title{
Chronic Levodopa Treatment Alters Basal and Dopamine Agonist- Stimulated Cerebral Glucose Utilization
}

\author{
Thomas M. Engber, Zvi Susel, Shirley Kuo, and Thomas N. Chase \\ Experimental Therapeutics Branch, National Institute of Neurological Disorders and Stroke, Bethesda, Maryland 20892
}

The effect of chronic levodopa administration on the functional activity of the basal ganglia and its output regions was evaluated by means of the 2-deoxyglucose (2-DG) autoradiographic technique in rats with a unilateral 6-hydroxydopamine lesion of the nigrostriatal pathway. The rates of local cerebral glucose utilization were studied under basal conditions as well as in response to challenge with a selective $D_{1}$ or $D_{2}$ dopamine-receptor agonist. Levodopa (100 mg/ $\mathbf{k g} / \mathrm{d}$, i.p.) was administered for $19 \mathrm{~d}$ either continuously via infusion with an osmotic pump or intermittently by twicedaily injections. Following a 3-d washout, glucose utilization was found to be decreased by both levodopa regimens in the nucleus accumbens; intermittent levodopa also decreased glucose utilization in the entopeduncular nucleus, subthalamic nucleus, ventrolateral thalamus, ventromedial thalamus, ventroposterolateral thalamus, and lateral habenula. In control (lesioned and treated chronically with saline) rats, the $D_{1}$ agonist SKF 38393 (5 $\mathrm{mg} / \mathrm{kg}$, i.v.) increased 2-DG uptake in the substantia nigra pars reticulata and entopeduncular nucleus ipsilateral to the lesion by $84 \%$ and $56 \%$, respectively. Both continuous and intermittent levodopa blunted the SKF 38393-induced elevation in glucose metabolism in the substantia nigra pars reticulata, while intermittent levodopa also attenuated the increase in the entopeduncular nucleus. The $D_{2}$ agonist quinpirole $(0.4 \mathrm{mg} / \mathrm{kg}$, i.v.) did not increase glucose utilization in any brain region in control animals; following intermittent levodopa treatment, however, quinpirole increased 2-DG uptake by $64 \%$ in the subthalamic nucleus and by $39 \%$ in the deep layers of the superior colliculus on the ipsilateral side. These findings indicate that chronic levodopa treatment has long-lasting effects on the functional activity of brain regions within the basal ganglia as well as in regions that are targets of basal ganglia output. The effects of chronic levodopa are dependent on the treatment regimen employed: Administration of levodopa on an intermittent basis causes alterations in glucose utilization that are more pronounced and widespread than those of the same daily dose of levodopa given by continuous infusion. Our results also suggest that chronic levodopa treatment differentially alters $D_{1}$ and $D_{2}$ receptormediated striatal output, decreasing $D_{1}$ output through the striatonigral and striatoentopeduncular pathways and increasing $D_{2}$ output through the striatopallidal pathway.

\footnotetext{
Received Apr. 9, 1990; revised Aug. 3, 1990; accepted Aug. 9, 1990.

We wish to thank Jonathan A. Glass for technical assistance.

Correspondence should be addressed to Thomas N. Chase, M.D., NINDS, NIH, Building 10, Room 5C103, 9000 Rockville Pike, Bethesda, MD 20892.

Copyright (C) 1990 Society for Neuroscience $0270-6474 / 90 / 123889-07 \$ 03.00 / 0$
}

Symptoms of Parkinson's disease presumably result from the loss of dopaminergic neurons projecting from the substantia nigra to the corpus striatum. Most parkinsonian patients initially experience symptomatic relief from replacement therapy with levodopa, the precursor of dopamine. Prolonged treatment with levodopa, however, often leads to the development of motorresponse complications such as peak dose dyskinesias and variations in the antiparkinsonian response (Marsden and Parkes, 1977). Clinical studies suggest that these adverse effects may reflect continuing degeneration of dopamine neurons as well as secondary postysynaptic changes (Mouradian et al., 1987, 1988). The nature of the secondary postsynaptic changes caused by long-term levodopa treatment is not known. Indeed, earlier preclinical studies of the behavioral and biochemical effects of chronic levodopa administration have produced variable results that offered little insight into the pathogenesis of motor-response complications (revicwed by Jenner et al., 1986).

Factors possibly accounting for the inconsistency of the foregoing data include differences in the response measured and in the intermittence of the levodopa treatment. The importance of both parameters is illustrated by a recent study on the effect of chronic levodopa treatment on rotational behavior in rats with a unilateral 6-hydroxydopamine lesion of the nigrostriatal dopamine pathway (Engber el al., 1989): Chronic administration of levodopa by twice-daily injections exerted opposite effects on rotation induced by selective $D_{1}$ and $D_{2}$ dopamine receptor agonists, with the response to $\mathrm{D}_{1}$ agonist reduced and the response to $\mathrm{a}_{2}$ agonist increased. However, administration of the same daily dose by continuous infusion resulted in no change in the rotational response to the $D_{1}$ agonist and only a moderate increase in the response to the $D_{2}$ agonist. Neither $D_{1}$ nor $\mathrm{D}_{2}$ dopamine receptors in the striatum were affected by continuous or intermittent levodopa treatment, though the activity of striatal glutamic acid decarboxylase (GAD), the synthetic enzyme for the inhibitory neurotransmitter GABA, increased following intermittent but not continuous levodopa (Juncos et al., 1989). These results suggest that chronic levodopa administration alters neuronal systems situated downstream from striatal dopamine receptors, an idea supported by the finding that intermittent levodopa treatment decreases the responsiveness of neurons in the substantia nigra pars reticulata, a region innervated by striatal efferents, to both a systemically administered $D_{1}$ agonist and iontophoretically applied GABA (Weick et al., 1990).

As an approach to identifying the neuronal circuits in the basal ganglia affected by chronic levodopa administration, we have now employed the 2-deoxyglucose (2-DG) autoradiographic method for measuring local cerebral glucose utilization 
(Sokoloff et al., 1977). This technique has been used previously to identify neuronal circuits activated acutely by intrastriatal dopamine (Brown and Wolfson, 1983), systemic levodopa (Trugman and Wooten, 1986), apomorphine (Kozlowski and Marshall, 1980; Wooten and Collins, 1983), and selective $\mathrm{D}_{1}$ and $\mathrm{D}_{2}$ agonists (Trugman and Wooten, 1987). Here, we report that chronic levodopa treatment alters basal glucose utilization as well as glucose utilization changes in response to selective $D_{1}$ and $\mathrm{D}_{2}$ agonists in several brain regions, and, furthermore, that these effects are dependent on the levodopa treatment schedule.

\section{Materials and Methods}

6-Hydroxydopamine lesions. Male Sprague-Dawley rats (250-300 gm) were housed in groups of 3 or 4 on a 12-hr light/dark cycle with free access to food and water. Under sodium pentobarbital anesthesia (50 $\mathrm{mg} / \mathrm{kg}$, i.p.), rats were placed in a stereotaxic frame with the incisor bar positioned $4.5 \mathrm{~mm}$ below the interaural line. Each animal received an injection of 6-hydroxydopamine $\mathrm{HCl}(8 \mu \mathrm{g}$ in $4 \mu$ l saline with $0.02 \%$ ascorbate over $8 \mathrm{~min}$ ) into the left median forebrain bundle by means of a Harvard infusion pump (Harvard Apparatus, South Natick, MA). Stereotaxic injections were placed $4.0 \mathrm{~mm}$ anterior to the interaural line, $1.3 \mathrm{~mm}$ lateral to the midline, and $8.4 \mathrm{~mm}$ ventral to the surface of the skull, according to the atlas of Paxinos and Watson (1982). Following a 3-week recovery period, rats were tested for rotational response to apomorphine $(0.05 \mathrm{mg} / \mathrm{kg}$, s.c.), and a homogeneous group (mean total turns $\pm 1 \mathrm{SD}$ ) was selected for further study.

Chronic treatments. One week after rotation screening, selected rats were divided into 3 chronic treatment groups: (1) continuous saline plus intermittent saline (saline group), (2) continuous levodopa plus intermittent saline (continuous levodopa group), and (3) continuous saline plus intermittent levodopa (intermittent levodopa group). Continuous treatments were given via Alzet ${ }^{\circledR}$ osmotic pumps (Model 2ML2, Alza Corp., Palo Alto, CA) implanted intraperitoneally under sodium pentobarbital anesthesia; all animals were given an injection of penicillin $\mathrm{G}$ benzathine $(15,000 \mathrm{U}$, i.m.) after pump implantation to prevent infection. Intermittent treatments consisted of intraperitoneal injections given in a volume of $0.3 \mathrm{ml}$ twice daily. Levodopa was administered in the form of levodopa methyl ester ( $L-\beta-3,4-$ dihydroxyphenylalanine methyl ester hydrochloride), a more stable and soluble pro-drug whose ester moiety is rapidly hydrolyzed by nonspecific plasma esterases to form levodopa (Cooper et al., 1984). Levodopa methyl ester was administered by both continuous and intermittent treatment regimens at a dose of $100 \mathrm{mg} / \mathrm{kg} / \mathrm{d}$ in combination with benserazide $(25 \mathrm{mg} / \mathrm{kg} / \mathrm{d}$, dissolved in the levodopa solution), a peripheral decarboxylase inhibitor. In calculating the concentration of levodopa methyl ester to be used in the osmotic pump, the rats' anticipated average weight over the course of the study was estimated to assure dose equivalency of the continuous and intermittent treatments. Thus, levodopa methyl ester was placed in the osmotic pumps at a concentration of $343 \mathrm{mg} / \mathrm{ml}$ and pumped at a rate of $4.26 \mu 1 / \mathrm{hr}$ (data provided by $\Lambda$ lza Corp.), yielding a dose of $100 \mathrm{mg} / \mathrm{kg} / \mathrm{d}$ for a $350-\mathrm{gm}$ rat. These 2 levodopa treatment regimens have been shown to produce equivalent daily plasma levodopa levels (Engber et al., 1989). The chronic treatment for all 3 groups was given for $19 \mathrm{~d}$ because this was the mean pumping duration for the batch of osmotic pumps used in this study (data provided by Alza Corp.). Prior to the 2-DG procedure, the animals were allowed a 3-d drug washout in order to distinguish the possible effects of chronic exposure to levodopa from the acute response to levodopa administration; also, it was necessary to wash the levodopa out completely before animals were challenged with a $D_{1}$ or $D_{2}$ agonist.

Experimental design and 2-deoxyglucose procedure. Three experiments were conducted in rats treated chronically with either saline, continuous levodopa, or intermittent levodopa. In the baseline experiment, glucose utilization was measured following chronic treatment in the absence of an acute drug challenge. In the second experiment, rats were given an intravenous injection of the $D_{1}$ dopamine agonist SKF 38393 at a dose of $5.0 \mathrm{mg} / \mathrm{kg} 10 \mathrm{~min}$ before administration of ${ }^{14} \mathrm{C}-2$ deoxyglucose. In the third experiment, chronically treated rats were challenged with an intravenous injection of the $\mathrm{D}_{2}$ agonist quinpirole at a dose of $0.4 \mathrm{mg} / \mathrm{kg} 10 \mathrm{~min}$ before administration of ${ }^{14} \mathrm{C}$-2-deoxyglucose. The doses of both SKF 38393 and quinpirole are 4-fold higher than those utilized as a challenge dose in a previous study of the effect of chronic levodopa treatment on rotational behavior (Engber et al., 1989); the lower doses used previously are sufficient to produce vigorous contralateral rotation in 6-hydroxydopamine-lesioned rats that lasts for 3-4 hr. SKF 38393 and quinpirole were given $10 \mathrm{~min}$ before ${ }^{14} \mathrm{C}-2$ deoxyglucose because, in our experience, there is a 10-15-min latency before rotational behavior begins following intraperitoneal administration of these drugs.

Local cerebral glucose utilization was measured by the ${ }^{14} \mathrm{C}$-2-deoxyglucose method (Sokoloff et al., 1977). On the day of the experiment, polyethylene catheters were placed in the femoral artery and femoral vein of each rat under halothane anesthesia. Animals were restrained by a partial-body plaster cast and secured on a lead brick. At least $2 \mathrm{hr}$ were allowed for recovery from the halothane anesthesia. ${ }^{14} \mathrm{C}$-2-deoxyglucose $(125 \mu \mathrm{Ci} / \mathrm{kg}$; specific activity, $50-55 \mathrm{mCi} / \mathrm{mmol}$; DuPont $/ \mathrm{NEN}$, Boston, MA) was administered over $10 \mathrm{sec}$ through the femoral venous catheter. Over the subsequent $45 \mathrm{~min}$, timed arterial blood samples were collected from the femoral arterial catheter for plasma glucose concentration (Beckman glucose analyzer II) and ${ }^{14} \mathrm{C}$ activity determinations. Animals were then killed by intravenously injected sodium pentobarbital. The brains were rapidly removed, frozen in chillcd isopentane $\left(-45^{\circ} \mathrm{C}\right)$, and stored at $-70^{\circ} \mathrm{C}$. Coronal sections were cut at a thickness of $20 \mu \mathrm{m}$ in a cryostat at $-20^{\circ} \mathrm{C}$, thaw-mounted on coverslips, and dried on a slide warmer at $60^{\circ} \mathrm{C}$. The brain sections were apposed to Kodak OM-1 x-ray film; films were exposed for $14 \mathrm{~d}$ along with a series of calibrated ${ }^{14} \mathrm{C}$-methylmethacrylate standards (Amersham, $\mathrm{Ar}$ lington Heights, IL). Optical densities in brain regions identified according to the atlas of Paxinos and Watson (1982) and in standards were measured with a Zeiss IBAS II image analysis system.

Data analysis and statistics. Tissue concentrations of ${ }^{14} \mathrm{C}$-2-deoxyglucose were calculated by comparing the optical densities of the tissue with those of the calibrated standards. Rates of glucose utilization were computed from the local tissue ${ }^{14} \mathrm{C}$-2-deoxyglucose concentration according to the operational equation of the method (Sokoloff et al., 1977). Results from each animal represent the mcan of 4 measurements per brain region.

Data were analyzed by analysis of variance followed by Duncan's new multiple range test. All 9 treatment groups ( $n=4$ rats in each group) were included in a single analysis of glucose utilization in each individual brain region; analyses were performed separately for the lesioned (left) and intact (right) brain hemispheres. Data from the lesioned and intact hemispheres were compared by means of a 2 -factor analysis of variance with repeated measures followed by Dunn's multiple comparisons of paired means. Statistical significance for all tests was taken as $p<0.05$.

Drugs. Drugs used in this experiment were obtained from the following sources: 6-hydroxydopamine $\mathrm{HCl}$, levodopa methyl ester $\mathrm{HCl}$, and apomorphine $\mathrm{HCl}$ (Sigma, St. Louis, MO); benserazide (gift of Hoffmann-LaRoche, USA); ( \pm SKF $38393 \mathrm{HCl}$ and (-)quinpirole $\mathrm{HCl}(\mathrm{Re}-$ search Biochemicals, Natick, MA); penicillin G benzathine (Bicillin; Wyeth, Philadelphia, PA); sodium pentobarbital (Nembutal; Abbott Laboratories, Chicago, IL); halothane (Fluothane; Ayerst Laboratories, New York, NY). Drug doses are expressed in terms of the weights of their salts.

\section{Results}

Unilateral lesion of the nigrostriatal pathway altered local glucose utilization rates in several brain regions, as can be seen by comparing data from the lesioned and intact brain hemispheres in saline-treated baseline animals (Table 1). The rate of glucose utilization increased significantly ipsilateral to the lesion in the globus pallidus (up 13\%) and lateral habenula (up 11\%). Significant reductions in glucose utilization ipsilateral to the lesion were observed in the lateral striatum (down 11\%) and deep layers of the superior colliculus (down 7\%).

Chronic treatment with levodopa on either an intermittent or continuous basis also affected the rate of glucose utilization in a number of brain regions in comparison with saline-treated control animals (Table 1). In the intermittently treated baseline group, metabolic activity was decreased ipsilateral to the 6-hydroxydopamine lesion in the ventroposterolateral thalamus (down 30\%) and contralateral to the lesion in the entopeduncular 
nucleus (down 27\%) and lateral habenula (down 28\%). Bilateral reductions in glucose utilization were observed following intermittent levodopa in the nucleus accumbens (down 15\% ipsilateral, $21 \%$ contralateral), ventrolateral thalamus (down $28 \%$ and $26 \%$ ), ventromedial thalamus (down $29 \%$ and $27 \%$ ), and subthalamic nucleus (down $34 \%$ and $30 \%$ ). In the continuously treated baseline group, glucose metabolism was decreased in the nculeus accumbens bilaterally (down $16 \%$ on both sides), but was unaffected in other brain regions.

The acute administration of the $D_{1}$ agonist SKF 38393 alone altered the rate of glucose utilization in several areas (Table 1, saline-treated rats). The largest increases in 2-DG uptake occurred in the ipsilateral substantia nigra pars reticulata (up 84\%) and entopeduncular nucleus (up 56\%). SKF 38393 also elevated glucose utilization in 2 additional regions, the lateral striatum and somatosensory region of the frontoparietal cortex (up 25\% and $22 \%$, respectively). Glucose metabolism decreased in response to SKF 38393 in the ipsilateral lateral habenula (down $54 \%$ ) and anterior cingulate cortex (down 25\%) and the contralateral nucleus accumbens (down 16\%).

Chronic treatment with either continuous or intermittent levodopa blunted the SKF 38393-induced elevation in 2-DG uptake in the substantia nigra pars reticulata: Though glucose utilization increased in both levodopa treatment groups (up 72\% in the continuous group, $58 \%$ in the intermittent group; Table 1), the rate of glucose utilization was significntly lower than that in the saline-treated rats (Fig. 1). SKF 38393 elevated glucose metabolism by $43 \%$ in the ipsilateral entopeduncular nucleus of rats treated with continuous levodopa (Table 1); the rate of glucose utilization in this region did not differ from that of the saline-treated controls. In rats treated with intermittent levodopa, however, the rate of glucose utilization in the entopeduncular nucleus was significantly lower than that of both the saline and the continuous levodopa groups and did not differ significantly from baseline values (Table 1). Glucose metabolism was also increased by SKF 38393 in the continuous levodopa group in the ventroposterolateral thalamus (up 33\%) and in the intermittent levodopa group in the subthalamic nucleus (up $37 \%$ ). In the continuous levodopa group, 2-DG uptake decreased bilaterally in response to SKF 38393 in the lateral habenula (down $57 \%$ ipsilateral, $28 \%$ contralateral) and unilaterally in the anterior cingulate cortex (down 26\% ipsilateral). In the intermittent levodopa group, glucose utilization was reduced only in the lateral habenula (down 57\%) on the ipsilateral side.

The acute administration of the $\mathrm{D}_{2}$ agonist quinpirole alone had effects on regional glucose metabolism that were less widespread than those of SKF 38393 (Table 1). In saline-treated animals, quinpirole did not increase $2-\mathrm{DG}$ uptake in any brain region, but decreased it bilaterally in the nucleus accumbens (down 31\% ipsilateral, 33\% contralateral) and lateral habenula (down 39\% ipsilateral, 30\% contralateral). On the other hand, substantial increases over baseline values in the rate of glucose utilization occurred in the subthalamic nucleus (up $64 \%$ ipsilateral, 40\% contralateral) and deep layers of the superior colliculus (up 39\% ipsilateral) in rats treated with intermittent levodopa (Fig. 2); in these animals, glucose utilization was reduced by quinpirole in the ipsilateral lateral habenula (down 41\%). Following treatment with continuous levodopa, quinpirole elevated glucose metabolism in the ipsilateral ventroposterolateral thalamus (up 33\%) and contralateral subthalamic nucleus (up $30 \%$ ) and reduced it bilaterally in the lateral habenula (down $39 \%$ ipsilateral, $25 \%$ contralateral).


Figure 1. Representative ${ }^{14} \mathrm{C}$-2-deoxyglucose autoradiographs showing pattern of local cerebral glucose utilization in rats with unilateral lesion of nigrostriatal pathway treated chronically with either saline $(A)$, continuous levodopa $(B)$, or intermittent levodopa $(C)$ and challenged acutely with $D_{1}$ agonist SKF 38393 . In saline-treated control animals, SKF 38393 caused a substantial increase in glucose utilization in the substantia nigra pars reticulata ipsilateral to the lesion (left side of figure). Both continuous and intermittent levodopa treatment blunted the elevation in glucose utilization in the ipsilateral substantia nigra caused by SKF 38393. 
Table 1. Local cerebral glucose utilization following chronic continuous or intermittent levodopa

\begin{tabular}{|c|c|c|c|c|c|c|}
\hline \multirow[b]{2}{*}{ Brain region } & \multirow[b]{2}{*}{ Side } & \multicolumn{3}{|l|}{ Baseline } & \multicolumn{2}{|c|}{ SKF 38393 challenge } \\
\hline & & Saline & $\begin{array}{l}\text { Continuous } \\
\text { levodopa }\end{array}$ & $\begin{array}{l}\text { Intermittent } \\
\text { levodopa }\end{array}$ & Saline & $\begin{array}{l}\text { Continuous } \\
\text { levodopa }\end{array}$ \\
\hline \multirow[t]{2}{*}{ Frontoparietal cortex, motor } & Lesioned & $82.6 \pm 3.9$ & $78.3 \pm 5.0$ & $70.9 \pm 3.8$ & $94.6 \pm 6.1$ & $79.6 \pm 8.1$ \\
\hline & Intact & $90.5 \pm 2.3$ & $86.0 \pm 7.4$ & $78.6 \pm 4.4$ & $88.5 \pm 6.7$ & $75.9 \pm 8.5$ \\
\hline \multirow{2}{*}{$\begin{array}{l}\text { Frontoparietal cortex, } \\
\text { somatosensory }\end{array}$} & Lesioned & $80.2 \pm 4.2$ & $74.9 \pm 5.1$ & $65.7 \pm 3.8^{a}$ & $98.1 \pm 5.4^{b}$ & $84.0 \pm 6.0$ \\
\hline & Intact & $88.6 \pm 3.5$ & $84.9 \pm 5.3$ & $78.4 \pm 5.4$ & $101.9 \pm 11.0$ & $81.1 \pm 8.5^{d}$ \\
\hline \multirow[t]{2}{*}{ Nucleus accumbens } & Lesioned & $81.6 \pm 4.7$ & $68.8 \pm 2.9^{b}$ & $69.2 \pm 3.9^{b}$ & $79.6 \pm 4.4^{a}$ & $61.6 \pm 5.5^{b . d}$ \\
\hline & Intact & $85.9 \pm 4.5$ & $72.6 \pm 3.7^{b}$ & $68.8 \pm 3.6^{b}$ & $72.2 \pm 4.2^{b}$ & $59.9 \pm 5.9^{b}$ \\
\hline \multirow[t]{2}{*}{ Anterior cingulate cortex } & Lesioned & $92.9 \pm 5.7$ & $86.1 \pm 10.6$ & $81.7 \pm 6.6^{a}$ & $69.4 \pm 7.2^{a, b}$ & $63.6 \pm 6.3^{a, b, c}$ \\
\hline & Intact & $94.3 \pm 4.4$ & $89.6 \pm 10.6$ & $86.1 \pm 6.3$ & $78.8 \pm 7.2$ & $70.1 \pm 5.9^{b}$ \\
\hline \multirow[t]{2}{*}{ Striatum, lateral } & Lesioned & $79.4 \pm 2.8^{a}$ & $78.4 \pm 4.7^{a}$ & $66.0 \pm 3.9^{a}$ & $99.1 \pm 4.3^{b}$ & $81.4 \pm 6.5^{d}$ \\
\hline & Intact & $89.6 \pm 5.4$ & $87.4 \pm 5.8$ & $75.0 \pm 4.9$ & $97.4 \pm 5.2$ & $77.4 \pm 6.4^{d}$ \\
\hline \multirow[t]{2}{*}{ Striatum, medial } & I esioned & $78.0+3.2$ & $78.2 \pm 4.2$ & $67.9 \pm 5.5$ & $85.5 \pm 4.4$ & $74.2 \pm 4.1^{a}$ \\
\hline & Intact & $79.4 \pm 4.3$ & $80.9 \pm 4.9$ & $67.7 \pm 6.1$ & $80.0 \pm 5.1$ & $66.0 \pm 5.2$ \\
\hline \multirow[t]{2}{*}{ Striatum, caudal } & Lesioned & $79.1 \pm 5.4$ & $70.9 \pm 4.8$ & $63.7 \pm 6.8$ & $97.9 \pm 10.0^{\alpha}$ & $88.7 \pm 14.0^{a}$ \\
\hline & Intact & $75.9 \pm 6.2$ & $69.2 \pm 5.8$ & $63.5 \pm 2.7$ & $69.9 \pm 9.1$ & $62.9 \pm 8.2$ \\
\hline \multirow[t]{2}{*}{ Globus pallidus } & Lesioned & $58.9 \pm 2.8^{a}$ & $57.8 \pm 2.8^{a}$ & $54.0 \pm 3.3^{a}$ & $67.7 \pm 3.8^{a}$ & $60.7 \pm 7.7^{a}$ \\
\hline & Intact & $52.1 \pm 1.6$ & $50.2 \pm 3.3$ & $43.9 \pm 2.8$ & $57.6 \pm 4.5$ & $51.2 \pm 5.4$ \\
\hline \multirow[t]{2}{*}{ Ventrolateral thalamus } & Lesioned & $90.5 \pm 6.9$ & $78.2 \pm 5.2$ & $65.0 \pm 7.3^{b}$ & $99.8 \pm 8.5$ & $90.6 \pm 9.9$ \\
\hline & Intact & $95.2 \pm 4.7$ & $81.3 \pm 5.9$ & $70.5 \pm 6.4^{b}$ & $95.7 \pm 10$ & $90.9 \pm 8.5$ \\
\hline \multirow[t]{2}{*}{ Ventromedial thalamus } & Lesioned & $105.3 \pm 9.7$ & $96.3 \pm 8.1$ & $75.3 \pm 7.1^{b}$ & $101.6 \pm 8.7$ & $99.5 \pm 9.9$ \\
\hline & Intact & $105.0 \pm 6.6$ & $97.0 \pm 9.2$ & $76.6 \pm 5.9^{b}$ & $101.5 \pm 8.7$ & $100.8 \pm 8.4$ \\
\hline \multirow[t]{2}{*}{ Ventroposterolateral thalamus } & Lesioned & $81.6 \pm 5.6$ & $69.1 \pm 4.2$ & $56.9 \pm 5.8^{b}$ & $91.3 \pm 4.0$ & $91.6 \pm 9.0^{c}$ \\
\hline & Intact & $79.4 \pm 4.4$ & $68.2 \pm 5.2$ & $61.1 \pm 4.4$ & $87.3 \pm 9.5$ & $81.2 \pm 4.7$ \\
\hline \multirow[t]{2}{*}{ Entopeduncular nucleus } & Lesioned & $49.2 \pm 4.3$ & $48.9 \pm 3.0$ & $41.0 \pm 5.1$ & $76.8 \pm 4.3^{a, b}$ & $70.1 \pm 6.5^{a, b, c}$ \\
\hline & Intact & $54.8 \pm 3.7$ & $46.4 \pm 3.7$ & $40.2 \pm 3.9^{b}$ & $47.2 \pm 4.1$ & $46.6 \pm 4.0$ \\
\hline \multirow[t]{2}{*}{ Subthalamic nucleus } & Lesioned & $78.1 \pm 4.6$ & $67.4 \pm 3.9$ & $52.7 \pm 4.7^{b}$ & $82.4 \pm 2.5$ & $75.2 \pm 8.3$ \\
\hline & Intact & $82.8 \pm 4.4$ & $67.8 \pm 3.1$ & $57.9 \pm 5.2^{b}$ & $76.8 \pm 4.5$ & $69.2 \pm 9.2$ \\
\hline \multirow[t]{2}{*}{ Lateral habenula } & Lesioned & $118.5 \pm 15.3^{a}$ & $122.3+7.7^{a}$ & $111.2 \pm 11.6^{a}$ & $54.8 \pm 6.5^{a . b}$ & $52.2 \pm 4.3^{a, b, c}$ \\
\hline & Intact & $107.1 \pm 10.3$ & $106.6 \pm 7.9$ & $77.6 \pm 7.1^{b, e}$ & $103.3 \pm 5.3$ & $77.0 \pm 2.5^{b . c, d}$ \\
\hline \multirow[t]{2}{*}{ Substantia nigra pars reticulata } & Lesioned & $52.0 \pm 4.9$ & $44.1 \pm 4.6$ & $41.8 \pm 4.3$ & $95.5 \pm 3.3^{a, b}$ & $75.6 \pm 8.0^{a . b . c . d}$ \\
\hline & Intact & $51.7 \pm 4.1$ & $44.8 \pm 3.9$ & $40.4 \pm 3.2$ & $52.8 \pm 6.0$ & $52.1 \pm 6.7$ \\
\hline \multirow[t]{2}{*}{ Superior colliculus, deep layers } & Lesioned & $75.3 \pm 5.2^{a}$ & $68.0 \pm 3.8$ & $60.5 \pm 4.3$ & $82.4 \pm 1.4$ & $85.5 \pm 9.7^{a}$ \\
\hline & Intact & $81.2 \pm 5.7$ & $72.2 \pm 4.0$ & $63.8 \pm 4.3$ & $78.0 \pm 2.3$ & $78.0 \pm 9.2$ \\
\hline
\end{tabular}

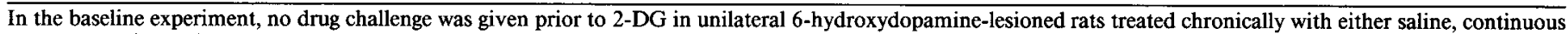

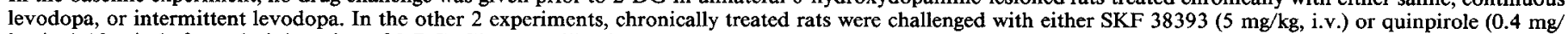

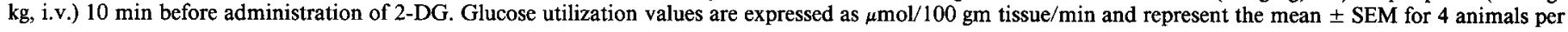
group.

${ }^{a} p<0.05$ versus intact side.

${ }^{b} p<0.05$ versus saline baseline group.

${ }^{c} p<0.05$ versus baseline group with corresponding chronic treatment.

${ }^{d} p<0.05$ versus saline group with corresponding drug challenge.

${ }^{e} p<0.05$ versus continuous levodopa group.

\section{Discussion}

The 2-DG autoradiographic technique for measuring local cerebral glucose utilization was used to examine the influence of striatal dopamine deafferentation, acute administration of selective $\mathrm{D}_{1}$ and $\mathrm{D}_{2}$ dopamine agonists, and chronic replacement with the dopamine precursor levodopa on the functional activity of the basal ganglia and its target regions. The effects of unilateral 6-hydroxydopamine lesion of the nigrostriatal pathway and the administration of $D_{1}$ and $D_{2}$ agonists on local cerebral glucose utilization observed in this study are in essential agreement with the findings of other investigators. Unilateral lesion with 6-hydroxydopamine increased glucose utilization in the globus pallidus and lateral habenua ipsilateral to the lesion, as has been reported (Kozlowski and Marshall, 1980; Wooten and Collins,
1981). Stimulated increases in 2-DG uptake reportedly reflect primarily increased sodium pump activity in nerve terminals and dendrites, because these cellular elements of the nervous system have the highest surface-to-volume ratio (Mata et al., 1980). Therefore, the observed effects of 6-hydroxydopamine lesion on glucose utilization are most likely the result of disinhibition and increased firing rates of neurons in the striatopallidal and entopeduncular-lateral habenula pathways.

The effects of the $D_{1}$ agonist SKF 38393 and the $D_{2}$ agonist quinpirole on regional glucose metabolism in 6-hydroxydopamine-lesioned rats have previously been described (Trugman and Wooten, 1987), and their findings with the $D_{1}$ agonist are consistent with those of the present study. In both studies, SKF 38393 markedly increased 2-DG uptake in the substantia nigra pars reticulata and entopeduncular nucleus and decreased it in 


\begin{tabular}{|c|c|c|c|}
\hline \multirow{2}{*}{$\begin{array}{l}\text { SKF } 38393 \\
\text { challenge } \\
\text { Intermittent } \\
\text { levodopa }\end{array}$} & \multicolumn{3}{|c|}{ Quinpirole challenge } \\
\hline & Saline & $\begin{array}{l}\text { Continuous } \\
\text { levodopa }\end{array}$ & $\begin{array}{l}\text { Intermittent } \\
\text { levodopa }\end{array}$ \\
\hline $79.3 \pm 6.5$ & $72.5 \pm 3.5$ & $81.7 \pm 4.0$ & $68.2 \pm 2.0$ \\
\hline $84.4 \pm 3.3$ & $79.7 \pm 3.8$ & $84.2 \pm 4.8$ & $72.9 \pm 2.7^{b}$ \\
\hline $79.1 \pm 7.2^{d}$ & $72.8 \pm 2.0^{a}$ & $82.8 \pm 4.0$ & $68.7 \pm 5.3$ \\
\hline $84.3 \pm 4.8$ & $85.6 \pm 3.6$ & $92.1 \pm 6.3$ & $76.6 \pm 2.0$ \\
\hline $61.8 \pm 3.1^{b . d}$ & $56.5 \pm 4.8^{b}$ & $57.6 \pm 3.1^{b}$ & $56.4 \pm 2.3^{b}$ \\
\hline $63.2 \pm 3.2^{h}$ & $57.2 \pm 5.1^{b}$ & $61.3 \perp 3.6^{b}$ & $59.4 \pm 3.3^{b}$ \\
\hline $66.7 \pm 3.3^{a, b}$ & $75.7 \pm 5.9$ & $80.1 \pm 8.5^{a}$ & $71.1 \pm 3.8^{a}$ \\
\hline $73.2 \pm 3.7$ & $78.3 \pm 5.1$ & $85.0 \pm 8.9$ & $78.5+3.7$ \\
\hline $78.9 \pm 3.7^{d}$ & $71.8 \pm 2.5$ & $80.8 \pm 5.9$ & $80.1 \pm 5.1^{a}$ \\
\hline $81.3 \pm 2.8$ & $77.8 \pm 2.0$ & $86.3 \pm 5.8$ & $88.0 \pm 6.5$ \\
\hline $71.2 \pm 5.4$ & $69.1 \pm 2.8$ & $80.5 \pm 5.3$ & $70.6 \pm 4.6$ \\
\hline $67.0 \pm 4.9$ & $70.0 \pm 1.9$ & $79.5 \pm 5.3$ & $66.4 \pm 6.0$ \\
\hline $64.3 \pm 4.4^{d}$ & $69.0 \pm 4.4$ & $82.7 \pm 8.2^{a}$ & $65.5 \pm 2.7$ \\
\hline $55.0 \pm 3.1^{b}$ & $64.5 \pm 5.4$ & $70.7 \pm 3.3$ & $56.8 \pm 4.5$ \\
\hline $60.1 \pm 3.1^{a}$ & $51.6 \pm 4.0$ & $58.4 \pm 3.8$ & $55.8 \pm 4.5^{a}$ \\
\hline $53.0 \pm 3.3$ & $49.8 \pm 4.8$ & $53.7 \pm 3.2$ & $50.8 \pm 3.5$ \\
\hline $82.3 \pm 6.3$ & $81.5 \pm 5.6$ & $99.2 \pm 10.2$ & $85.3 \pm 3.5$ \\
\hline $78.4 \pm 5.1$ & $81.5 \pm 7.2$ & $96.2 \pm 9.2$ & $81.1 \pm 4.2$ \\
\hline $95.0 \pm 4.7$ & $88.3 \pm 6.0$ & $111.9 \pm 7.7$ & $91.3 \pm 4.0$ \\
\hline $92.0 \pm 3.9$ & $91.7 \pm 7.9$ & $105.3 \pm 6.8$ & $93.0 \pm 4.0$ \\
\hline $75.1 \pm 6.1$ & $73.4 \pm 5.8$ & $92.0 \pm 11.0^{c}$ & $73.0 \pm 3.1$ \\
\hline $68.6 \pm 4.8$ & $73.2 \pm 8.7$ & $84.9 \pm 8.4$ & $68.7 \perp 3.3$ \\
\hline $53.8 \pm 5.1^{a, d, e}$ & $45.5 \pm 3.3$ & $48.3 \pm 3.9$ & $51.7 \pm 1.3$ \\
\hline $41.6 \pm 4.2^{b}$ & $44.0 \pm 3.6$ & $50.1 \pm 4.6$ & $48.8 \pm 1.3$ \\
\hline $72.1 \pm 6.3^{c}$ & $77.5 \pm 5.0$ & $86.5 \pm 5.5$ & $86.4 \pm 9.4^{c}$ \\
\hline $69.0 \pm 4.2$ & $77.1 \pm 4.5$ & $87.9 \pm 6.2^{c}$ & $80.8 \pm 7.4^{c}$ \\
\hline $48.2 \pm 3.7^{a, b, c}$ & $72.8 \pm 5.1^{b}$ & $74.9 \pm 2.3^{b . c}$ & $65.4 \pm 4.8^{b . c}$ \\
\hline $81.0 \pm 6.5^{b, d}$ & $75.2 \pm 5.4^{b}$ & $80.3 \pm 2.0^{b, c}$ & $75.1 \pm 6.0^{b}$ \\
\hline $66.0 \pm 5.2^{a, c, d}$ & $52.5 \pm 5.4$ & $53.6 \pm 6.5$ & $49.6 \pm 4.6$ \\
\hline $50.4 \pm 3.9$ & $53.1 \pm 6.0$ & $54.6 \pm 6.1$ & $49.1 \pm 4.3$ \\
\hline $76.6 \pm 3.5^{a}$ & $76.4 \pm 11.2^{a}$ & $85.6 \pm 6.7$ & $84.3 \pm 3.6^{a, c}$ \\
\hline $66.7 \pm 2.4$ & $82.3 \pm 12.5$ & $88.0 \pm 7.1$ & $73.0 \pm 3.5$ \\
\hline
\end{tabular}

the lateral habenula ipsilateral to the lesion. However, unlike the previous report, glucose utilization did not increase in any brain region following the administration of the $\mathrm{D}_{2}$ agonist quinpirole in our study. This is most likely due to the dose of quinpirole used $(0.4 \mathrm{mg} / \mathrm{kg})$, which is midway between the lowest effective dose $(1.0 \mathrm{mg} / \mathrm{kg})$ and the highest ineffective dose $(0.1$ $\mathrm{mg} / \mathrm{kg}$ ) used by Trugman and Wooten. In our study, quinpirole decreased glucose utilization bilaterally in both the nucleus accumbens and the lateral habenula. They reported no change in the nucleus accumbens and a unilateral (ipsilateral) decrease in the lateral habenula in response to quinpirole at doses of 1.0 $\mathrm{mg} / \mathrm{kg}$ or greater. An important finding of both studies, though, is that the $D_{1}$ agonist has a much more pronounced effect than the $\mathrm{D}_{2}$ agonist on glucose metabolism in the substantia nigra pars reticulata and entopeduncular nucleus. These regions are
2 of the targets of striatal efferent projections and serve as the major output nuclei of the basal ganglia (Graybiel and Ragsdale, 1979).

Chronic levodopa treatment was found to reduce glucose utilization in several brain regions when measured following complete washout. These glucose-utilization changes differ from the acute response to levodopa (Trugman and Wooten, 1986), suggesting that they result from withdrawal following chronic exposure to levodopa. Intermittent administration of levodopa (twice-daily injections) had a more widespread effect on regional glucose metabolism than the same daily dose given by continuous infusion: While both forms of levodopa administration decreased 2-DG uptake in the nucleus accumbens, intermittent levodopa also caused reductions in the ventrolateral thalamus, ventromedial thalamus, ventroposterolateral thalamus, entopeduncular nucleus, subthalamic nucleus, and lateral habenula. With the exception of the nucleus accumbens and entopeduncular nucleus, these regions contain relatively low dopamine receptor densities (Boyson et al., 1986), and all but 1 of thcse regions (ventroposterolateral thalamus) are situated 2 synapses downstream from the striatum. Therefore, changes in glucose utilization probably do not reflect a direct action of levodopa in these regions, but, rather, are the consequence of the action of levodopa (via conversion to dopamine) on dopamine receptors in the striatum; this chronic activation of striatal dopamine receptors results in alterations in neuronal mechanisms situated downstream from these receptors. Because 3 of these regions (ventrolateral thalamus, ventromedial thalamus, lateral habenula) are secondary projections of the striatum and lie outside of the basal ganglia, our findings suggest that chronic intermittent levodopa treatment has long-lasting effects on basal ganglia output.

Activation of either $D_{1}$ or $D_{2}$ dopamine receptors in the striatum can modify basal ganglia output, though it has been suggested that different striatal efferent pathways mediate the actions of these 2 receptor subtypes (Herrera-Marschitz and Ungerstedt, 1984). In order to determine the effect of chronic levodopa on $D_{1}$ receptor-mediated mechanisms, SKF 38393 was administered prior to $2-\mathrm{DG}$ in animals treated chronically with either continuous or intermittent levodopa. Both continuous and intermittent levodopa diminished the SKF 38393induced increase in glucose utilization in the substantia nigra pars reticulata, and, in addition, intermittent levodopa blunted the SKF 38393-induced increase in 2-DG uptake in the entopeduncular nucleus. These findings suggest that chronic levodopa treatment, especially when administered on an intermittent basis, attenuates the response of striatonigral and striatoentopeduncular neurons to SKF 38393. The results of 2 previous investigations on the effects of chronic levodopa replacement in 6-hydroxydopamine-lesioned rats are consistent with this view. In one study, chronic intermittent levodopa diminished the rotational response to an acute challenge with SKF 38393 (Engber et al., 1989), while, in the other, it decreased the responsiveness of neurons in the substantia nigra pars reticulata to both systematically administered SKF 38393 and iontophoretic GABA (Weick et al., 1990). Together, these 3 studies provide evidence based on regional cerebral glucose utilization, rotational behavior, and electrophysiology that chronic levodopa treatment reduces $\mathrm{D}_{1}$ receptor-mediated basal ganglia output.

While chronic levodopa administration decreased $D_{1}$ receptor-mediated glucose utilization responses, it appeared to in- 


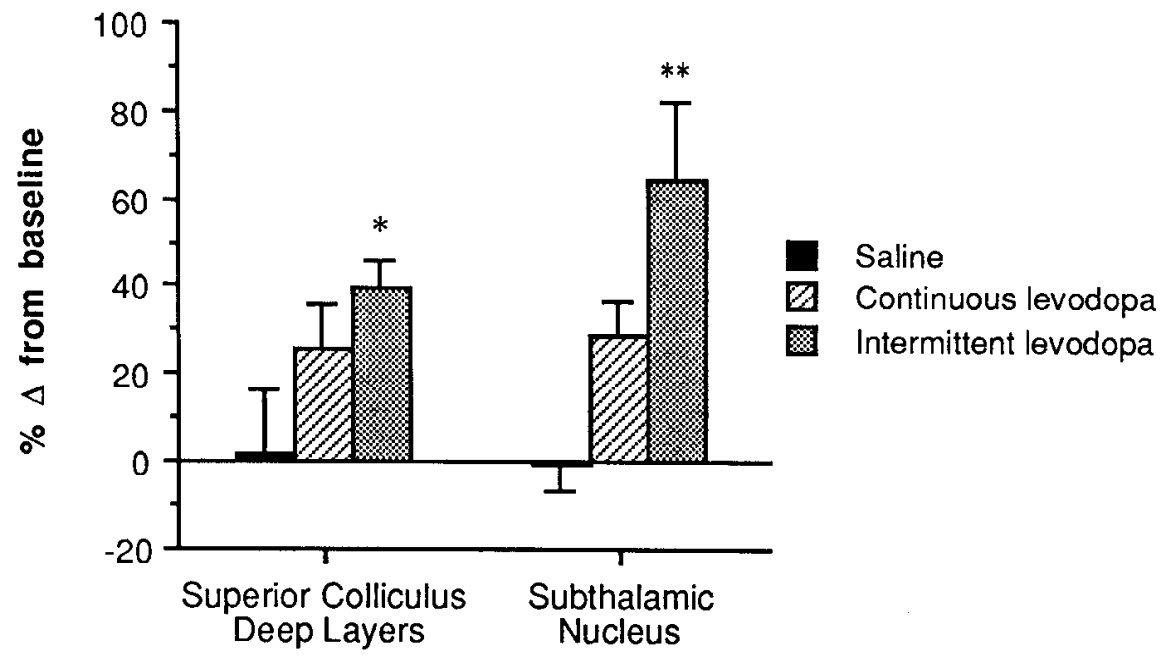

Figure 2. Effect of chronic levodopa treatment on glucose-utilization response to acute challenge with $\mathrm{D}_{2}$ agonist quinpirole in ipsilateral deep layers of superior colliculus and subthalamic nucleus of rats with unilateral lesion of nigrostriatal pathway. Glucose utilization values in the quinpirole-challenged animals were divided by the mean value from the baseline group given the same chronic treatment (Table 1) and are expressed as the percentage change from baseline. The effect of quinpirole on glucose utilization in both the deep layers of the superior colliculus and the subthalamic nucleus was significantly greater in rats treated with intermittent levodopa than in saline-treated control animals, while the effect of quinpirole in the continuous levodopa group did not differ significantly from that in the controls. Values for percentage change from baseline were compared by analysis of variance followed by Duncan's new multiple range test. Error bars denote SEM. ${ }^{*}, p<0.05 ;{ }^{* *}, p<0.01$ versus saline; $n=4$ animals per group.

crease $\mathrm{D}_{2}$ receptor-mediated responses. These findings also parallel those of our earlier investigation of rotational behavior (Engber et al., 1989), in which chronic intermittent levodopa not only decreased the rotational response to SKF 38393, but also increased the rotational response to quinpirole. In the present study, administration of quinpirole prior to 2-DG did not increase glucose utilization in any brain region in saline-treated rats, but it resulted in a substantial increase in 2-DG uptake in the subthalamic nucleus and deep layers of the superior colliculus in rats treated chronically with intermittent levodopa. Both of these regions play an important role in mediating dopamine receptor-stimulated basal ganglia output. The subthalamic nucleus is influenced by striatal output via the globus pallidus; an increase in glucose utilization in response to quinpirole in this region most likely reflects increased activity in the pallidal-subthalamic pathway. The deep layers of the superior colliculus are innervated by efferents from the substantia nigra pars reticulata, and this region has been reported to be involved in mediating dopamine agonist-induced rotation in 6-hydroxydopamine-lesioned rats (DiChiara et al., 1982).

Unlike the $D_{1}$ agonist SKF 38393, the $D_{2}$ agonist quinpirole had no effect on glucose utilization in the other 2 regions that are the targets of striatal efferents, the substantia nigra pars reticulata and the entopeduncular nucleus; quinpirole did, however, have a greater effect than SKF 38393 on 2-DG uptake in the subthalamic nucleus, suggesting a greater influence on striatal output through the globus pallidus. This differential effect of $D_{1}$ and $D_{2}$ agonists on striatal cfferent pathways lends firm support to the idea that striatal $\mathrm{D}_{2}$ receptor-associated output is mediated primarily through the globus pallidus, while striatal $D_{1}$ receptor-associated output is mediated primarily through the substantia nigra pars reticulata and entopeduncular nucleus (Ogren and Fuxe, 1988). The fact that the $\mathrm{D}_{1}$ agonist also increased glucose utilization in the subthalamic nucleus of levodopa-treated rats suggests that, at least under certain conditions, there is some cross talk between these projection pathways, perhaps mediated by the local axon collaterals of medium spiny neurons within the striatum (Wilson and Groves, 1980). The high density of $D_{1}$ binding sites in the substantia nigra pars reticulata and entopeduncular nucleus (Boyson et al., 1986) has prompted speculation that the incrcasc in glucose utilization in these regions caused by SKF 38393 may be due to a direct action on these receptors (Trugman and Wooten, 1987). Data from the present study neither confirm nor refute this hypothesis. However, the question of whether a systemically administered $D_{1}$ agonist acts on striatal rather than nigral or entopeduncular $D_{1}$ receptors may not be of crucial importance; studies employing striatal lesions have shown that $D_{1}$ receptors in the substantia nigra pars reticulata and entopeduncular nucleus are located primarily on the terminals of striatal efferent neurons (Barone et al., 1987; Filloux et al., 1987). Therefore, regardless of the site of action, agonists of the $D_{1}$ receptor will act on striatonigral and striatoentopeduncular neurons, whether at the cell body or terminal end of the neuron. Because both the globus pallidus and the subthalamic nucleus contain relatively few $\mathrm{D}_{2}$ receptors (Boyson et al., 1986), $\mathrm{D}_{2}$ receptor-associated effects on this striatal efferent pathway are almost certainly mediated by striatal $\mathrm{D}_{2}$ receptors.

The effect of chronic levodopa treatment on local cerebral glucose utilization has previously been examined in monkeys with MPTP-induced parkinsonism (Porrino et al., 1987). These animals were treated with levodopa $(300 \mathrm{mg} / \mathrm{d}$, p.o.) for 60 $120 \mathrm{~d}$, and 2-DG was administered $45 \mathrm{~min}$ after the last dose of levodopa. Glucose utilization was increased substantially in the subthalamic nucleus (up 104\%) and to a lesser extent (up $31 \%$ ) in the internal segment of the globus pallidus (the primate equivalent of the rodent entopeduncular nucleus); glucose utilization was not significantly increased in the substantia nigra pars reticulata. No comparison was made between the acute and chronic effects of levodopa. If, however, acutely administered levodopa substantially increases $2-D G$ uptake in the substantia nigra pars reticulata and internal segment of the globus pallidus 
in monkeys with a lesion of the nigrostriatal pathway, as it does in rats (Trugman and Wooten, 1986), these findings would suggest that chronic levodopa treatment decreases dopamine receptor-stimulated striatal output through the substantia nigra pars reticulata and internal segment of the globus pallidus. The marked increase in glucose utilization in the subthalamic nucleus of the MPTP-lesioned monkeys suggests that striatal output through the external segment of the globus pallidus is unaffected or, perhaps, even enhanced by chronic levodopa administration. The rodent and primate data, taken together, indicate that chronic levodopa treatment differentially alters the responses of the striatal efferent pathways to dopamine receptor stimulation.

Long-term oral levodopa therapy in parkinsonian patients often leads to the development of motor-response complications believed to result from continuing degeneration of dopamine neurons as well as secondary postsynaptic changes (Mouradian et al., 1987, 1988). The results of the present study provide insight into the nature of the postsynaptic changes caused by chronic levodopa administration. Chronic levodopa treatment has long-lasting effects on basal ganglia output and appears to have opposite effects on $D_{1}$ and $D_{2}$ receptor-mediated striatal output. Because concurrent stimulation of $D_{1}$ and $D_{2}$ receptors is gencrally required for the expression of dopamine-agonist effects (Walters et al., 1987), this dissociation between $D_{1}$ and $\mathrm{D}_{2}$ receptor-mediated mechanisms resulting from chronic levodopa treatment may contribute to the pathogenesis of motorresponse complications in parkinsonian patients. These motorresponse complications can be ameliorated by switching patients to continuous intravenous infusion of levodopa (Mouradian et al., 1987). In the present study, continuous infusion of levodopa, a treatment regimen that produces daily plasma levels equivalent to those of the intermittent treatment regimen (Engber et al., 1989), had effects on local cerebral glucose utilization that were less pronounced and widespread than those due to intermittent levodopa. Because nigrostriatal dopamine neurons have been shown to be tonically active (Bunney et al., 1973), levodopa replacement by continuous infusion may be more physiological than oral intermittent therapy. The results of this study indicate that chronic levodopa administration causes alterations in basal ganglia output, particularly in the balance between $D_{1}$ and $D_{2}$ dopamine receptor-mediated mechanisms, and that the development of these alterations is related to the intermittence of the levodopa treatment regimen.

\section{References}

Barone P, Tucci I, Parashos SA, Chase TN (1987) D-1 dopamine receptor changes after striatal quinolinic acid lesion. Eur J Pharmacol 138:141-145.

Boyson SJ, McGonigle P, Molinoff PB (1986) Quantitative autoradiographic localization of the $D_{1}$ and $D_{2}$ subtypes of dopamine receptors in rat brain. $J$ Neurosci $6: 3177-3188$.

Brown LL, Wolfson LI (1983) A dopamine-sensitive striatal efferent system mapped with $\left[{ }^{14} \mathrm{C}\right]-2$-deoxyglucose in the rat. Brain Res 261: 213-229.

Bunney BS, Walters JR, Roth RH, Aghajanian G (1973) Dopaminergic neurons: effects of antipsychotic drugs and amphetamine on single cell activity. J Pharmacol Exp Ther 185:560-571.

Cooper DR, Marrel C, Testa B, Van de Waterbeemd H, Quinn N, Jenner P, Marsden CD (1984) L-Dopa methyl ester: a candidate for chronic systemic delivery of $\mathbf{L}$-dopa in Parkinson's disease. Clin Neuropharmacol 7:89-98.

DiChiara G, Morelli M, Imperato A, Porceddu ML (1982) A reevaluation of the role of superior colliculus in turning behaviour. Brain Res 237:61-77.
Engber TM, Susel Z, Juncos JL, Chase TN (1989) Continuous and intermittent levodopa differentially affect rotation induced by $D_{1}$ and $\mathrm{D}_{2}$ dopamine agonists. Eur J Pharmacol 168:291-298.

Filloux FM, Wamslcy JK, Dawson TM (1987) Presynaptic and postsynaptic $D_{1}$ dopamine receptors in the nigrostriatal system of the rat brain: a quantitative autoradiographic study using the selective $D_{1}$ antagonist [ $\left.{ }^{3} \mathrm{H}\right] \mathrm{SCH}$ 23390. Brain Res 408:205-209.

Graybiel AM, Ragsdale CW (1979) Fiber connections of the basal ganglia. Prog Brain Res 51:239-283.

Herrera-Marschitz M, Ungerstedt U (1984) Evidence that striatal efferents relate to different dopamine receptors. Brain Res 323:269278.

Jenner P, Boyce S, Marsden CD (1986) Effect of repeated L-DOPA administration on striatal dopamine receptor function in the rat. In: Recent developments in Parkinson's disease (Fahn S, Marsden CD, Jenner P, Teychenne P, eds), pp 189-203. New York: Raven.

Juncos JL, Engber TM, Raisman R, Susel Z, Thibaut F, Ploska A, Agid Y, Chase TN (1989) Continuous and intermittent levodopa differentially affect basal ganglia function. Ann Neurol 25:473-478.

Kozlowski MR, Marshall JF (1980) Plasticity of $\left[{ }^{14} \mathrm{C}\right]-2-$ deoxy-D-glucose incorporation into neostriatum and related structures in response to dopamine neuron damage and apomorphine replacement. Brain Res 197:167-183.

Marsden CD, Parkes JD (1977) Success and problems of long-term levodopa therapy in Parkinson's disease. Lancet 1:345-349.

Mata M, Fink DJ, Gainer H, Smith CB, Davidsen L, Savaki H, Schwartz WJ, Sokoloff L (1980) Activity-dependent energy metabolism in rat posterior pituitary primarily reflects sodium pump activity. $\mathbf{J}$ Neurochem 34:213-215.

Mouradian MM, Juncos JL, Fabbrini G, Chase TN (1987) Motor fluctuations in Parkinson's disease: pathogenetic and therapeutic studies. Ann Neurol 22:475-479.

Mouradian MM, Juncos JL, Fabbrini G, Schlegel J, Bartko JJ, Chase TN (1988) Motor fluctuations in Parkinson's disease: central pathophysiological mechanisms, Pt II. Ann Neurol 24:372-378.

Ogren SO, Fuxe $K$ (1988) $D_{1}$ - and $D_{2}$-receptor antagonists induce catalepsy via different efferent striatal pathways. Neurosci Lett 85 : 333-338.

Paxinos G, Watson C (1982) The rat brain in stereotaxic coordinates. New York: Academic.

Porrino LJ, Burns RS, Crane AM, Palombo E, Kopin IJ, Sokoloff L (1987) Local cerebral metabolic effects of L-dopa therapy in 1-methyl-4-phenyl-1,2,3,6-tetrahydropyridine-induced parkinsonism in monkeys. Proc Natl Acad Sci USA 84:5995-5999.

Sokoloff L, Reivich M, Kennedy C, DesRosiers MH, Patlak CS, Pettigrew KD, Sakurada O, Shenohara M (1977) The $\left[{ }^{14} \mathrm{C}\right]$-2-deoxyglucose method for the measurement of local cerebral glucose utilization: theory, procedure, and normal values in the conscious and anesthetized albino rat. J Neurochem 28:879-916.

Trugman JM, Wooten GF (1986) The effects of L-DOPA on regional cerebral glucose utilization in rats with unilateral lesions of the substantia nigra. Brain Res 379:264-274.

Trugman JM, Wooten GF (1987) Selective $D_{1}$ and $D_{2}$ dopamine agonists differentially alter basal ganglia glucose utilization in rats with unilateral 6-hydroxydopamine substantia nigra lesions. J Neurosci 7: 2927-2935.

Walters JR, Bergstrom DA, Carlson JH, Chase TN, Braun AR (1987) $D_{1}$ dopamine receptor activation required for postsynaptic expression of $D_{2}$ agonist effects. Science 236:719-722.

Weick BG, Engber TM, Susel Z, Chase TN, Waltcrs JR (1990) Responses of substantia nigra pars reticulata neurons to GABA and SKF 38393 in 6-hydroxydopamine lesioned rats are differentially affected by continuous and intermittent levodopa administration. Brain Res 523:16-22.

Wilson CJ, Groves PM (1980) Fine structure and synaptic connections of the common spiny neuron of the rat neostriatum: a study employing intracellular injection of horseradish peroxidase. J Comp Neurol 194: 599-615.

Wooten GF, Collins RC (1981) Metabolic effects of unilateral lesion of the substantia nigra. J Neurosci 1:285-291.

Wooten GF, Collins RC (1983) Effects of dopaminergic stimulation on functional brain metabolism in rats with unilateral substantia nigra lesions. Brain Res 263:267-275. 